\title{
A CLINICAL STUDY ON SAFETY AND EFFICACY OF FORMOTEROL AND TIOTROPIUM COMBINATION COMPARED TO FORMOTEROL AND TIOTROPIUM WITH ROFLUMILAST COMBINATION IN TREATMENT OF MODERATE TO SEVERE CHRONIC OBSTRUCTIVE PULMONARY DISEASE PATIENTS
}

\section{KAVITHA DEVI M $^{1}$, SARUMATHY $\mathrm{S}^{2}$, SARATH LAL SASIDHARAN², MEHANAZ SHAIK ${ }^{2}$, GOTTIMUKKALA SANDEEP ${ }^{2}$, VUNNAM RAJASEKHAR ${ }^{2}$, DAMODHARAN $\mathbf{N}^{2 *}$}

\begin{abstract}
${ }^{1}$ Department of Pulmonary Medicine, SRM Medical College Hospital and Research Centre, SRM University, Kattankulathur, Kancheepuram - 603203, Tamil Nadu, India. ${ }^{2}$ Department of Pharmacy Practice, SRM College of Pharmacy, SRM University, Kattankulathur, Kancheepuram - 603203, Tamil Nadu, India. Email: dharan75@gmail.com
\end{abstract}

Received: 09 August 2017, Revised and Accepted: 30 November 2017

ABSTRACT

Objectives: The objective of this study is to assess the safety and efficacy of formoterol and tiotropium combination compared to formoterol and tiotropium with roflumilast combination in treatment of moderate-to-severe chronic obstructive pulmonary disease (COPD) patients on inhaled combination therapy.

Methods: A comparative prospective interventional study was carried out in 61 COPD patients who were visiting the pulmonary medicine ward during 6 months (October 2016 to March 2017). The patients were randomized into two groups. Group A patients received a combination of formoterol and tiotropium, whereas Group B patients received roflumilast along with formoterol and tiotropium combination. Spirometry tests were done to both the study population. Forced expiratory volume in 1 second (FEV1) and forced vital capacity (FVC) were noted at the initial visit and after the treatment. All the statistical analyses such as mean and p values were calculated using SPSS 14.0 version software.

Results: The average age group of the study population was $57.63 \pm 8.3$ years. Comorbid condition such as diabetes mellitus was higher in the study groups. Comparison of spirometry reports before and after drug administration in both groups was done. FEV1 and FVC were found to be statistically significant between the study group $(0.001, \mathrm{p}<0.05)$. The average mean change of FEV1 before and after treatment in Group B was found to be improved as compared to Group B (0.66).

Conclusion: Tiotropium and formoterol with roflumilast combination were found to be safe and effective in moderate-to-severe COPD patients.

Keywords: Roflumilast, Tiotropium, Formoterol, Spirometry.

(C) 2018 The Authors. Published by Innovare Academic Sciences Pvt Ltd. This is an open access article under the CC BY license (http://creativecommons. org/licenses/by/4. 0/) DOI: http://dx.doi.org/10.22159/ajpcr.2018.v11i3.21871

\section{INTRODUCTION}

Chronic obstructive pulmonary disease (COPD) is a common, preventable lung disorder characterized by progressive, poorly reversible airflow limitation often with systemic manifestations, in response to tobacco smoke or other harmful inhalational exposures. It is characterized by reduced expiratory airflow and the symptoms of a cough, sputum production, and dyspnea. The breathlessness associated with COPD develops over many years, is a major reason for seeking medical care and eventually limits daily activities [1].

COPD prevalence varies in different regions. A large epidemiological study of $>60,000$ interviewees from 11 countries of the Middle East, North Africa, and Pakistan (BREATHE study) reported an overall prevalence of $3.6 \%$ while the Asia-Pacific regional working group reported an overall prevalence of $6.3 \%$ across 12 Asian countries [2]. Studies also reported a high burden of disease, with a large proportion of patients experiencing exacerbations, comorbidities, limitations at work, difficulties in social and family activities and psychological distress. COPD is the fourth leading cause of the death and major morbidity factor for increased cost and health-care burden in the society [3]. The data for its early diagnosis is lacking which pose a major obstacle for its prevention, treatment decision-making, and further management outcomes. It has been categorized into different severities by Global Initiative for COPD (GOLD) guidelines and American Thoracic Society/European Respiratory Society guidelines [4]. The basic pathology of the COPD is characterized by decreased in reversible airway obstruction and an abnormal inflammatory response so the main goal is to improve the airflow and decrease inflammation [5]. Management of stable COPD should be based not only on addressing the current disease impact mainly by symptoms and activity limitation but also by reducing the patient's future risk of disease progression determined primarily by exacerbation frequency [6]. Exacerbation in COPD is an acute event characterized by worsening of the patients respiratory symptoms such as cough, sputum production, fever dyspnea, chest pain, sleep disturbance and anorexia, the common factors causing exacerbation are bacterial or viral respiratory tract infection. In clinical practice, patients still suffering from frequent exacerbations may already be treated with a long-acting beta-agonist and inhaled corticosteroids [7]. Since frequent exacerbations are associated with a high level of inflammation, it is logical to add an anti-inflammatory therapy to combination treatment to further reduce exacerbation risk [8]. Roflumilast is an anti-inflammatory treatment that reduces exacerbation frequency in a specific subgroup of COPD patients with severe airflow limitation, a previous history of exacerbations and symptoms of chronic cough and sputum [9]. Inhaled therapies, including bronchodilators and inhaled corticosteroids are the mainstay of this management strategy but are only modestly effective even when used in combination [10]. Roflumilast 
was approved by central drug standard control organization in 2013 for use as concomitant maintenance treatment of severe COPD along with bronchodilators and showed clinically significant improvements in health status of COPD patients.

Since no study has been conducted comparing roflumilast and formoterol-tiotropium combination, in rural south Indian population, we designed a comparative study on efficacy and safety of roflumilast in moderate-to-severe COPD patients.

\section{METHODS}

A comparative randomized control study was carried out in 61 COPD patients who were visiting the pulmonary medicine ward during 6 months (October 2016 to March 2017). The study has been conducted after getting approval from the Institutional Ethics Committee (Ethics Clearance number: 1060/IEC/2016). The consent was obtained from the hospital authorities, and the informed consent has been collected from the patients. The inclusion criteria were both genders aged more than 40 years, moderate-to-severe COPD patient, current or ex-smokers, with a smoking history, patient with other comorbid conditions. The exclusion criteria were patients with a history of bronchial asthma and other lung diseases, lower respiratory tract infections and pregnancy and lactation. Group A included 30 patients who received a combination of formoterol and tiotropium, whereas Group B patients $(n=31)$ received roflumilast along with formoterol and tiotropium combination. The patient history collection is done during the first visit, and the necessary information regarding patient's lifestyle, comorbid conditions, medication, medical history, family history, and physical examinations were collected. Basic information regarding the lifestyle modification and medication was given to the patients. The following spirometry test was done to the patients of Group A and Group B. The parameters such as forced expiratory volume in 1 second (FEV1) and forced vital capacity (FVC) were noted at baseline (initial visit,) and after the treatment $\left(12^{\text {th }}\right.$ weeks) for both the study population. All the statistical analyses such as mean and $\mathrm{p}$ values were calculated using SPSS 14.0 version software.

\section{RESULTS}

This interventional study has been carried out for 12 weeks in moderate-to-severe COPD patients. The demographic details such as age, smoking history, and comorbid conditions are depicted in Table 1. Table 2 shows the spirometry values before (initial visit) and after the treatment (12 $2^{\text {th }}$ weeks) in Group A and Group B patients.

The following adverse drug reaction such as diarrhea was observed in $10 \%$ of patients, weight loss $(23.3 \%)$, headache $(3.3 \%)$, back pain (3.3\%), insomnia (10\%), and decreased appetite $(13.3 \%)$ were observed in Group B patients treated with roflumilast.

\section{DISCUSSION}

Medical treatment for COPD is usually aimed at improving the clinical conditions of the patient by improving the value of pulmonary function test and reducing the frequency of exacerbations. Ferguson, roflumilast when used as a concomitant maintenance treatment for severe COPD along with bronchodilators it showed clinically significant improvements in health status of COPD patients [11]. Vincken and Vandevoorde, in earlier studies on COPD patients, concluded that etiology and acute effects of COPD was mostly prevalent in the age group above 60 years and is similar to our study as patients in the age above 60 years were found to be more in both groups [12].

Rodrigo et al., in earlier studies have identified that majority number of patients have a current history of smoking (more than 10 cigarettes per day) [13]. In the present study, the data obtained identified that $32 \%$ of patients were former smokers whereas $17 \%$ were current smokers and $51 \%$ were passive smokers. Barnes and Celli, in earlier studies, have identified that there are significant number of comorbid conditions in
Table 1: Demographic details of the study population

\begin{tabular}{lll}
\hline Parameters & \multicolumn{2}{l}{ Number of patients n=30 (\%) } \\
\cline { 2 - 3 } & Group A & Group B \\
\hline Age (years) & $6(19.3)$ & \\
$41-50$ & $11(35.4)$ & $5(16.6)$ \\
$51-60$ & $14(45.1)$ & $16(53.3)$ \\
$>60$ & $11(33.3)$ & $9(30)$ \\
Smoking history & $5(16.6)$ & $9(30)$ \\
Ex-smoker & $15(50)$ & $5(16.6)$ \\
Current & $11(36.6)$ & $16(53.3)$ \\
Non-smoker & $4(13.3)$ & $0(0)$ \\
Comorbid conditions & $10(30)$ & $13(43.3)$ \\
Diabetes mellitus & $10(30)$ & $2(6.7)$ \\
Hypertension & $15(50)$ \\
Others & & \\
Nil & &
\end{tabular}

Table 2: Spirometry reports of the study population

\begin{tabular}{llll}
\hline Parameters & $\begin{array}{l}\text { Group A } \\
\mathbf{n = 3 0}\end{array}$ & $\begin{array}{l}\text { Group B } \\
\mathbf{n = 3 0}\end{array}$ & Significance (p) \\
\hline $\begin{array}{llll}\text { FEV1 (mean } \pm \text { SD) } \\
\quad \text { At baseline }\end{array}$ & $0.95 \pm 0.23$ & $0.92 \pm 0.23$ & ${ }^{*} 0.001$ \\
$\quad$ After treatment & $1.15 \pm 0.257$ & $1.58 \pm 0.21$ & \\
FVC (Mean \pm SD) & & & \\
$\quad \begin{array}{l}\text { At baseline } \\
\text { After treatment }\end{array}$ & $1.94 \pm 0.581$ & $1.89 \pm 0.48$ & $* 0.001$ \\
$\begin{array}{l}\text { Average change } \\
\text { in mean FEV1 }\end{array}$ & 0.20 & 0.66 & - \\
after treatment & & & \\
\hline
\end{tabular}

* Statistically Significance at *p<0.05. FEV1: Forced expiratory volume in

1 second, FVC: Forced vital capacity, SD: Standard deviation

COPD patients, and in the present study, there were more number of patients with comorbid disease conditions such as diabetes mellitus and hypertension [14]. Gross and Glembycz in earlier studies, it has been concluded that roflumilast is safe [15]. In the present study, 53.3\% patients in the Group B have not reported any adverse drug reactions and $46.7 \%$ patients showed mild-to-moderate adverse drug reactions. Fabbri et al., in earlier studies, the FEV1 and FVC values showed significant improvement after the administration of roflumilast oncedaily oral tablet al.ng with other bronchodilators [16]. In this study, the FEV1 and FVC values showed an improvement of $60 \mathrm{ml}$ and $10 \mathrm{ml}$, respectively, at the end of the study which is similar to the above study. Wells et al., in a randomized, placebo-controlled trial of roflumilast study suggests for the first time that administration of roflumilast for 12 weeks can reduce lung inflammation and is beneficial in patients with moderate to severe COPD and is comparable to the present study as there is a significant improvement in spirometry values [17]. Calverley et al., in a REACT study protocol, the data were pooled from 14 randomized, double-blind, placebo-controlled studies of roflumilast in COPD patients, the most frequent adverse events occurring more commonly were diarrhea, weight loss and headache [18]. Currie and Clarie in a new approach to oral treatment has demonstrated that phosphodiesterase 4 (PDE4) inhibitor appear to confer benefit in improving lung function and health-related outcomes, while the oral route of administration may present a compliance and ease of administration over inhaled medication and is relevant to our study as PDE4 inhibitor improves the lung function [19]. Ulrik and Calverley studies suggest that roflumilast is beneficial for maintenance treatment of patients with severe COPD with chronic cough and a history of frequent exacerbations as add-on to treatment with long-acting bronchodilators and is relevant to our present study [20]. The study has been conducted only for 12 weeks, and hence, the exacerbations were not assessed in moderate-to-severe COPD patients. Anti-inflammatory properties of the drug have not been evaluated, and the patient's sample size is limited. 


\section{CONCLUSION}

Roflumilast was found to be safe and efficacious in moderate-to-severe COPD patients. When compared to the standard treatment, roflumilast, when given as an add-on therapy, has shown significant improvement in pulmonary function tests of patients.

\section{REFERENCES}

1. Global Initiative for Chronic Obstructive Lung Disease (GOLD). Global strategy for the diagnosis, management, and prevention of Chronic Obstructive Pulmonary Disease. Global Initiative for Chronic Obstructive Lung Disease (GOLD). Available from: . [Last updated on 2011]

2. Tageldin MA, Nafti S, Khan JA, Nejjari C, Beji M, Mahboub B, et al. Distribution of COPD-related symptoms in the middle east and north Africa: Results of the BREATHE study. Respir Med 2012;106 Suppl 2:S25-32.

3. Pauwels RA, Buist AS, Calverley PM, Jenkins CR, Hurd SS, GOLD Scientific Committee, et al. Global strategy for the diagnosis, management, and prevention of chronic obstructive pulmonary disease. NHLBI/WHO global initiative for chronic obstructive lung disease (GOLD) workshop summary. Am J Respir Crit Care Med 2001;163:1256-76

4. Standardization of spirometry, 1994 update. American thoracic society. Am J Respir Crit Care Med 1995;152:1107-36.

5. Altaf M, Masood QM, Ahamed TZ. Health related quality of life assessment using ST. George's respiratory questionnaire in chronic obstructive pulmonary disease patients on combined inhaled corticosteroids and bronchodilators. Int J Pharm Pharm Sci 2016;8:445-9.

6. Postma D, Anzueto A, Calverley P, Jenkins C, Make BJ, Sciurba FC, et al. A new perspective on optimal care for patients with COPD. Prim Care Respir J 2011;20:205-9.

7. Unni A, Jayaprakash AK, Yadhukrishnan MC, Umadevi P. Drug utilization pattern in chronic obstructive pulmonary disease inpatients at a tertiary care hospital. Int J Pharm Pharm Sci 2015;11:389-91.

8. Perera WR, Hurst JR, Wilkinson TM, Sapsford RJ, Müllerova H, Donaldson GC, et al. Inflammatory changes, recovery and recurrence at COPD exacerbation. Eur Respir J 2007;29:527-34.

9. Bhowmik A, Seemungal TA, Sapsford RJ, Wedzicha JA. Relation of sputum inflammatory markers to symptoms and lung function changes in COPD exacerbations. Thorax 2000;55:114-20.

10. Calverley PM, Rabe KF, Goehring UM, Kristiansen S, Fabbri LM, Martinez FJ, et al. Roflumilast in symptomatic chronic obstructive pulmonary disease: Two randomised clinical trials. Lancet 2009;374:685-94.

11. Ferguson GT. Recommendations for the management of COPD. Chest 2000; $117: 23$ S-8S

12. Vincken W, Vandevoorde J. Early detection of COPD: Etiology and acute effects. Respir Med 2007;101:525-30.

13. Salvi SS, Barnes PJ. Chronic obstructive pulmonary disease in nonsmokers. Lancet 2009;374:733-43.

14. Barnes PJ, Celli BR. Systemic manifestations and comorbidities of COPD. Eur Respir J 2009;33:1165-85.

15. Gross NJ, Glembycz MA. Treatment of COPD with roflumilast, a new PDE4 inhibitor. COPD J Chronic Obstr Pulm Dis 2010;7:141-53.

16. Fabbri LM, Calverley PM. Roflumilast in moderate to severe COPD treating with long acting bronchodilators: Two randomized clinical trials. Lancet 2009;374:695-703

17. Wells JM, Jackson PL, Viera L, Bhatt SP, Gautney J, Handley G, et al. A randomized, placebo-controlled trial of roflumilast. Effect on prolineglycine-proline and neutrophilic inflammation in chronic obstructive pulmonary disease. Am J Respir Crit Care Med 2015;192:934-42.

18. Calverley PM, Martinez FJ, Fabbri LM, Goehring UM, Rabe KF. Does roflumilast decrease exacerbations in severe COPD patients not controlled by inhaled combination therapy? The REACT study protocol. Int J Chron Obstruct Pulmon Dis 2012;7:375-82.

19. Currie GP, Clarie A. PDE-4 inhibitor in COPD: A new approach to oral treatment. Br J Clin Pharmacol 2007;65:803-10.

20. Ulrik CS, Calverley PM. Roflumilast: Clinical benefit in patients suffering from COPD. Clin Respir J 2010;4:197-201. 